\title{
O fluxo da informação na prática clínica dos médicos residentes: análise na perspectiva da medicina baseada em evidências
}

\author{
Maria Gorete Monteguti Savi \\ Mestre em ciência da informação pela Universidade Federal de \\ Santa Catarina - UFSC, Florianópolis, SC, Brasil - Bibliotecária \\ da Biblioteca Setorial do Centro de Ciências da Saúde (UFSC), \\ Florianópolis, SC, Brasil. \\ E-mail: orete@bu.ufsc.br
}

Edna Lucia da Silva

Doutora em ciência da informação pela Universidade Federal do Rio de Janeiro, UFRJ, Rio de Janeiro, Brasil. Professora do Departamento de Ciência da Informação, Centro de Ciências da Educação da Universidade Federal de Santa Catarina (UFSC), Florianópolis, SC, Brasil.

E-mail:ednalu@uol.com.br

\section{Resumo}

Pesquisa que analisa o fluxo da informação na prática clínica dos médicos residentes. Para tal, considera os preceitos da medicina baseada em evidências (MBE) e elege como lócus de pesquisa o Hospital Universitário da UFSC e como universo os médicos residentes atuantes nos seus ambulatórios. A relevância do desenvolvimento da pesquisa está amparada em alguns argumentos: reconhecimento da MBE na prática clínica como alternativa para dar suporte à decisão clínica, através da seleção das fontes de informação de maior evidência disponíveis na literatura médica; constatação que há lacuna na literatura nacional para estudos com médicos residentes, uma vez que a maioria das pesquisas enfoca a forma como médicos e professores da área de saúde usam os sistemas e serviços de informação; convicção que o uso de informação selecionada de forma criteriosa possibilitará uma prática clínica mais eficaz. A pesquisa identificou e analisou os processos envolvidos no fluxo informacional na prática clínica do médico, sob as perspectivas de seleção, acesso, recuperação e uso das fontes de informação. Apresenta um modelo de fluxo de informação ideal na perspectiva da MBE.

\section{Palavras-chave}

Fluxo da informação. Medicina baseada em evidências. Acesso à informação.

\author{
Information flow in the clinical practice of \\ resident physicians: an analysis from an \\ evidence-based medicine perspective
}

\begin{abstract}
This study analyses information flow in the clinical practice of resident physicians. To this end it considers the precepts of Evidence Based Medicine] (EBM), and focuses on resident physicians at UFSC University Hospital medical clinics. The relevance of this research project is underpinned by several reasons: the recognition of EBM in clinical practice as an alternative that can support clinical decisions, through the selection of information sources of greater evidence available in medical literature; verification that there is a lack of studies on resident physicians in the national literature - the majority of studies have focused on the manner that physicians and professors in health fields use the information systems and services; the conviction that the use of information selected according to criteria encourages more efficient clinical practice. This study identifies and analyses the processes involved in information flow in clinical practice by physicians from the perspectives of selection, access, retrieval and use of information sources. It presents an ideal model of information flow from the perspective of EBM.
\end{abstract}

\section{Keywords}

Information flow. Evidence Based Medicine. Information access. 


\section{INTRODUÇÃO}

A sociedade da informação foi se concretizando pela simbiose das evoluções e das revoluções que se traduzem nas concepções de mundo globalizado (BAUMAN, 2001; SANTOS, 2002), permeado pelas constantes inovações tecnológicas e pela criação de um ambiente societário de redes (CASTELLS, 2002), principalmente com o advento da Internet, que modificou os conceitos de local e global, de tempo e espaço. Diante dessa conjuntura torna-se necessária a utilização de meios que facilitem o fluxo da informação.

O fluxo da informação é o processo envolvido na transferência da informação de um emissor para um receptor. Neste novo cenário mundial, Barreto (1998) identifica algumas mudanças no fluxo da informação, tais como: a interação do receptor com a informação ocorre de forma direta, sem intermediários; o tempo de interação é definido pelo próprio receptor, inclusive o julgamento da relevância da informação; a estrutura da mensagem é definida pelo receptor de acordo com suas necessidades; e a facilidade de ir e vir por toda a dimensão da rede.

O foco desta pesquisa foi o fluxo da informação na prática clínica dos médicos residentes, usando como perspectiva para a análise os preceitos da Medicina Baseada em Evidências (MBE). A pesquisa foi conduzida para obter respostas às seguintes questões: Qual o fluxo da informação na prática clínica dos médicos residentes? Qual a relação entre os parâmetros utilizados pelos médicos residentes na seleção das fontes de informação e os preceitos metodológicos propostos pela MBE?

A relevância do desenvolvimento da pesquisa foi amparada em alguns argumentos: reconhecimento da MBE na prática clínica, como alternativa para dar suporte à decisão clínica, através da seleção das fontes de informação de maior evidência disponíveis na literatura médica; constatação de que há lacuna na literatura nacional para estudos com médicos residentes, uma vez que a maioria das pesquisas enfoca a forma como médicos e professores da área de saúde usam os sistemas e serviços de informação; convicção de que o uso de informação selecionada de forma criteriosa possibilitará uma prática clínica mais eficaz.

A pesquisa identificou e analisou os processos envolvidos no fluxo informacional na prática clínica do médico, sob as perspectivas de seleção, acesso, recuperação e uso das fontes de informação, possuindo como objetivos: analisar o fluxo da informação na prática clínica dos médicos residentes do HU da UFSC; verificar a relação com os preceitos recomendados pela MBE na etapa de acesso à informação e propor um modelo ideal de fluxo considerando a perspectiva da MBE.

\section{CONTEXTUALIZANDO A MEDICINA BASEADA EM EVIDÊNCIA}

Tradicionalmente, o médico toma suas decisões clínicas baseado na experiência profissional, na prática que prevalece por consenso e nas orientações de especialistas mais experientes. O saber e a prática médica acompanham a evolução da humanidade, trazendo consigo uma mistura de magia, de arte e de ciência baseada na repetição de experiências passadas, legados escritos, experiência pessoal, princípios humanitários e feeling (MARQUES, 2003; MARASCIULO; NASSAR, 2004).

Com a medicina baseada em evidências, tradução do inglês Evidence-Based Medicine (EBM), surge um novo padrão de prática médica (EVIDENCE-BASED MEDICINE WORKING GROUP, 1992). Para Drummond (2004a, p. 3), evidências externas são informações e dados "coletados, na literatura médica recente, cuja validade e importância são aferidas por determinados critérios”. A prática clínica com base na MBE pressupõe aplicação de método que interliga a experiência clínica e as evidências disponíveis na literatura científica.

A MBE tem suas bases filosóficas na França, na primeira metade do século 19, mais precisamente em 1830, com a teoria "medicine d'observation" por Pierre Charles Alexandre Louis (MARQUES, 2003; SACKETT et al., 1998). A definição clássica

Ci. Inf., Brasília, DF, v. 38, n. 3, p.177-191, set./dez., 2009 
de MBE é formulada por Sackett et al. (1996) nos seguintes termos: uso consciente, explícito e judicioso da melhor evidência disponível, integrado com a experiência clínica do médico e os valores e as preferências do paciente.

No processo da MBE:

- a melhor evidência de pesquisa significa pesquisa clinicamente relevante, com frequência a partir de ciências médicas básicas, mas especialmente partindo da pesquisa clínica focalizada nos pacientes para a acurácia e a precisão dos exames diagnósticos (incluindo o exame clínico), o poder dos indicadores prognósticos e a eficácia e a segurança dos esquemas terapêuticos, de reabilitação e preventivos. As novas evidências baseadas na pesquisa clínica invalidam os exames diagnósticos e tratamentos previamente aceitos, substituindo-os por novos exames que são mais poderosos, precisos, eficazes e seguros;

- a habilidade clínica é a capacidade de usar nossos conhecimentos clínicos e a experiência para identificar rapidamente o estado de saúde e o diagnóstico de cada paciente, seus riscos individuais e benefícios de intervenções propostas, bem como os valores e expectativas pessoais do paciente;

- os valores do paciente referem-se às preferências particulares, preocupações e expectativas que cada paciente traz à consulta e que devemos integrar nas decisões clínicas, se lhe forem úteis. (SACKETTT et al., 2003, p.19).

A metodologia de prática clínica da MBE envolve cinco etapas sucessivas (SACKETT et al., 1998; McKIBBON, 1998; DRUMMOND, 2004a; DUNCAN, SCHMIDT, 2004; CASTRO, 2006):

1. Formulação da questão clínica - significa converter a necessidade de informação (sobre diagnóstico, tratamento, prognóstico ou prevenção) em uma questão padronizada que possa ser efetivamente respondida. Ela deve considerar o PICO (Paciente, Indicador prognóstico ou Intervenção terapêutica ou diagnóstica para que possam ser Comparados com outra intervenção e associados a um Outcome = desfecho), Na prática clínica as questões podem ser classificadas como básicas (background) e aplicadas (foreground). As respostas para questões básicas dependem de conhecimento básico e são comumente relacionadas com etiologia, patogênese de doenças, mecanismos de ação e efeitos adversos de medicamentos. As questões aplicadas (foreground) têm relação mais direta com a conduta a ser adotada, seja a conduta terapêutica ou conduta diagnóstica, por exemplo, e pode estar também relacionada com o conhecimento de fatores indicadores de prognóstico (NOBRE; BERNARDO; JATENE, 2003).

2. Acesso à informação - significa selecionar e recuperar as melhores evidências para responder à questão formulada, sendo que essas evidências podem envolver a literatura científica, o diagnóstico laboratorial, a informação dos pares e, até mesmo, o exame clínico. Rodrigues (2000) amplia essa ideia, ressaltando que as informações que contribuem para a prática clínica podem ser encontradas em publicações científicas; repositórios de dados clínicos (prontuários manuais ou eletrônicos do paciente); repositórios de dados administrativos; software para suporte à decisão e informação em saúde interativa disponível na Internet.

3. Análise crítica da informação - significa avaliar as evidências em relação à validade interna (análise do conteúdo e resultados), à validade externa (aplicabilidade no contexto) e à validade estatística (importância dos dados). Devem ser consideradas as vantagens e as desvantagens de cada modelo de desenho de pesquisa para aplicação na categoria específica da questão, bem como os métodos estatísticos utilizados nos estudos.

4. Aplicação no contexto clínico - significa aplicar as evidências obtidas na prática clínica, integrando-as à experiência clínica e às características específicas do paciente e suas preferências.

5. Avaliação ou autoavaliação - significa analisar o processo para ajustes ou analisar o próprio desempenho. 
De acordo com os princípios básicos da MBE, a figura 1 apresenta as etapas do processo metodológico na prática clínica.

Do contato médico/paciente é elaborada a questão clínica, que deverá ser clara e pertinente ao problema. As informações que irão subsidiar todo o processo de decisão devem se valer da melhor evidência disponível, que deverá ser identificada, interpretada, integrada à realidade do paciente e, finalmente, aplicada à decisão clínica.

O processo de decisão clínica envolve a análise criteriosa e imparcial dos resultados das pesquisas; o respeito às preferências do paciente, que deverão estar devidamente esclarecidas, e às circunstâncias em que o paciente é atendido, através da verificação do estágio da doença e dos recursos disponíveis no local de atendimento.
O senso crítico e a vivência do profissional é que irão definir o ajuste do processo, a fim de garantir ao paciente maior probabilidade de benefícios.

\section{CONTEXTUALIZANDO O FLUXO INFORMACIONAL}

A comunicação científica é definida como todo o conjunto de atividades que se encontram associadas com a produção, a disseminação e o uso de informação, desde a busca de uma ideia para pesquisa até a aceitação da informação sobre os resultados dessa pesquisa como componente do conhecimento científico (GARVEY, 1979).

Entende-se por fluxo da informação o processo de transferência da informação de um emissor para um receptor. Para Barreto (1998, p.122), o

\section{FIGURA 1}

Etapas metodológicas da MBE na prática clínica

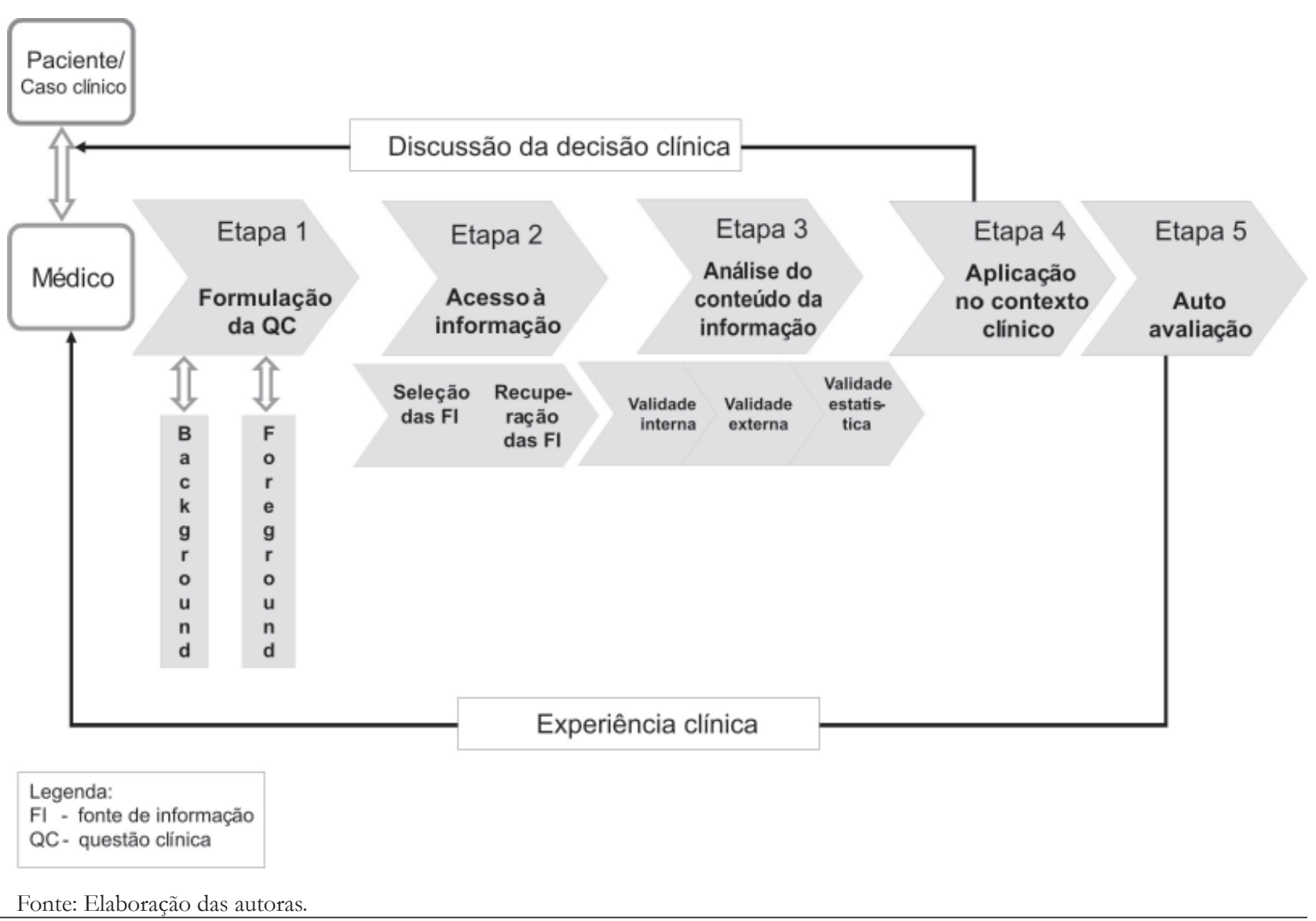


fluxo é um processo de mediação da informação gerada por uma fonte emissora e aceita por uma fonte receptora, podendo realizar uma das bases conceituais da ciência da informação: a geração de conhecimento no indivíduo e no seu espaço de convivência. Porém, para que ocorra conhecimento, a fonte receptora tem que entender a mensagem e agregar um diferencial, uma (re)elaboração de uma situação preexistente.

Barreto (1998, p. 122) confirma essa ideia, quando complementa que o fluxo de informação, ao utilizar os processos de comunicação

realiza a intencionalidade do fenômeno da informação, não almeja somente uma passagem. Ao atingir o público a que se destina deve promover uma alteração; aqueles que recebem e podem elaborar a informação estão expostos a um processo de desenvolvimento, que permite acessar um estágio qualitativamente superior nas diversas e diferentes gradações da condição humana.

Sob essa perspectiva, verifica-se que no fluxo da informação, quando ocorre essa alteração no status do receptor, ou seja, quando ele agrega um diferencial naquela informação, o fluxo opera em um sistema de criação da informação gerando o conhecimento.

Em estudo posterior, Barreto (2002) complementa essa ideia, ressaltando que o processo do fluxo da informação se move em dois níveis, nos quais

em um primeiro nível os fluxos internos de informação se movimentam entre os elementos de um sistema, que se orienta para sua organização e controle, seriam os fluxos internos ou de primeiro nivel [...] Os fluxos extremos são aqueles que por sua atuação mostram a essência do fenômeno de transformação, entre a linguagem do pensamento de um emissor -> a linguagem de inscrição do autor da informação -> e o conhecimento elaborado pelo receptor em sua realidade (BARRETO, 2002, p. 20).

Portanto, o fluxo da informação opera em um sistema de criação da informação que, através de um sistema de processamento, recuperação e uso, possibilitará sua apropriação pelo usuário (receptor) que poderá consolidá-la em conhecimento através de um processo de transformação de uma situação preexistente. A partir desse entendimento, será enfocado, nesta pesquisa, o fluxo de informação na prática clínica, ou seja, quando a informação acessada pelo médico causar uma mudança na situação existente ou interferir na decisão clínica, concentrando-se no que Barreto (2002) indica como fluxos extremos da informação.

Para Berto (2003), a mudança estrutural no fluxo da informação e do conhecimento reorientou conceitos e aspectos operacionais da comunicação, ao modificar a forma, o tempo e o espaço das interações humanas, através da ampliação da conexão e do acesso.

A estrutura da relação entre o fluxo da informação e o público a quem o conhecimento é dirigido vem se modificando com as TICs. Barreto (1999, p.376-377) amplia esta concepção, quando ressalta que tais mudanças operadas no status tecnológico das atividades de armazenamento e transmissão de informação vêm transformando continuamente a relação da informação com seus usuários e intermediários, bem como com a pesquisa em ciência da informação. O autor destaca como instabilidades mais notáveis: as mudanças na estrutura de informação; as mudanças no fluxo da informação; e os efeitos da globalização no fluxo e estrutura da informação.

A informação científica é disseminada de diferentes formas e, de acordo com Mueller (2000, p. 30), "a informação flui por muitos canais e diferentes tipos de documentos são produzidos, cujas características variam conforme o estágio da pesquisa e tipo de público a que se destina e o objetivo de quem comunica".

Os canais de informação são classificados, segundo suas características, em formais e informais, desempenhando importante papel para o desenvolvimento científico. Segundo Silva e Menezes (2005), os canais formais são destinados para a transferência de informação para uma comunidade e não para um indivíduo, 
tornam público o conhecimento produzido e são considerados oficiais, públicos e controlados por uma organização. Já os canais informais não são oficiais e não são controlados por uma organização, ocorrendo por meio do contato direto entre os pesquisadores ou intermediados pelo computador.

Com o advento das TICs surgem os canais eletrônicos de informação ou híbridos, pois possuem tanto características dos formais quanto dos informais. Targino (2000) apresenta algumas características dos canais eletrônicos, identificadas, principalmente, pelo grande público potencial, rapidez na atualização da informação, direção do fluxo selecionada pelo usuário e complexo processo de armazenamento e recuperação da informação.

De acordo com documento elaborado pelo Centro Latino-Americano e do Caribe de Informação em Ciências da Saúde - Bireme (2001, p. 7) "fonte de informação significa qualquer recurso que responda a uma demanda de informação por parte dos usuários, incluindo produtos e serviços de informação, pessoas ou rede de pessoas, programas de computador, etc.". Portanto, fontes de informação são caracterizadas como registros de dados ou de informações, disponíveis em qualquer suporte, e podem ser classificadas como primárias, secundárias e terciárias.

A Bireme (2001, p. 7) classifica como fontes primárias “os textos completos segundo os tipos clássicos da literatura científica (revistas, monografias, teses, etc.), como também outras fontes originais de dados hiper-textuais e numéricos". Entre os exemplos de novas fontes originais com dados textuais é indicada a Scientific Electronic Library Online (SCIELO).

Os documentos secundários são indicados pela Bireme (2001, p. 7) como os

que incluem todos os índices, bases de dados e diretórios, cujos registros fazem referência a fontes primárias, entidades e eventos na área de saúde. Incluem-se também os serviços de informação associados a essas fontes. O conjunto lembra, em linhas gerais, as unidades de referência na biblioteca tradicional.
Portanto, de acordo com a definição da Bireme, enquadram-se como publicações secundárias as bases de dados Lilacs, Medline, catálogo de revistas, diretórios de eventos e instituições, dentre outras.

Para a Bireme, as fontes terciárias são as "geradas com valor agregado a partir das fontes primárias e secundárias, e que têm objetivos didáticos ou de apoio à tomada de decisão de diferentes comunidades de usuários" (BIREME, 2001, p.7). Dentre os exemplos, temos a Biblioteca Cochrane.

Cabe ressaltar que na literatura há ausência de consenso terminológico em relação à distinção das fontes de informação e uma diversidade de possibilidades de classificação, principalmente após o desenvolvimento das TICs. Nesta pesquisa adotouse a classificação realizada pela Bireme (2001). A escolha dessa classificação deve-se ao fato de que contextualiza as fontes de informação em saúde no atual cenário informacional, seja através do suporte em que as fontes de informação se apresentam, seja através das características específicas do conteúdo das fontes de informação em saúde.

Com relação às fontes de informação, a expansão do conhecimento científico, a proliferação do número de publicações e, consequentemente, o grande volume de informação nas ciências, particularmente na ciência médica, fica evidenciada a importância das bases de dados.

A produção técnico-científica da área médica disponibilizada em bases de dados bibliográficas e/ou textuais pode ser referendada pelas mais representativas, tais como: Cochrane Library; Embase (Excerpta Medica Database); EBMR (Evidence Based Medicine Reviews); Lilacs (Literatura Latino Americana e do Caribe em Ciências da Saúde); Medline (Medical Literature Analysis and Retrieval System Online); SciELO (Scientific Electronic Library Online); Bireme e a WebofScience.

A Bireme tem incentivado a criação das Bibliotecas Virtuais em Saúde (BVS) para atender às demandas deste novo cenário informacional. Tais bibliotecas atuam como centros integradores e referenciais

Ci. Inf., Brasília, DF, v. 38, n. 3, p.177-191, set./dez., 2009 
de informação em saúde, e fazem parte de um projeto coordenado pela Bireme, que teve início na América Latina e no Caribe, atualmente expandido para alguns países europeus, como Espanha e Portugal. O funcionamento dessas bibliotecas está ancorado no uso de tecnologias da informação. Em 2007, a Bireme lançou o Portal de Evidências da BVS com o objetivo de reunir, organizar e oferecer acesso integrado às fontes de informação em saúde de melhor nível de evidência, de acordo com a metodologia proposta pela $\mathrm{MBE}$, bem como promover acesso às fontes de informação sobre a própria metodologia MBE.

$\mathrm{Na}$ área médica, a maioria das bases de dados indexa vários tipos de pesquisas, que podem ter maior ou menor aplicação na prática clínica. Para garantir resultados positivos no acesso e na recuperação da informação em bases de dados, é necessário que o médico desenvolva competências e habilidades para a elaboração de estratégia de busca e para o acesso às ferramentas tecnológicas e informacionais disponíveis.

Entende-se por estratégia de busca "a técnica ou conjunto de regras para tornar possível o encontro entre uma pergunta formulada e a informação armazenada em uma base de dados" (LOPES, 2002, p.61). O uso de uma estratégia de busca tem por objetivo a obtenção de maior grau de pertinência e relevância na recuperação da informação.

A estratégia de busca, na área médica, deve ser elaborada após a definição clara e objetiva da questão clínica, para extração das informações relevantes. A elaboração tem relação direta com o objetivo da questão e o tempo disponível para sua realização. Se o objetivo for obter toda a informação que existe, deverá ser realizada uma busca ampla, com o uso de termos mais gerais e uso reduzido de limitadores de busca. Tal estratégia tende a recuperar muitas informações, algumas relevantes e outras não. Assim, será necessário maior tempo na seleção das informações que atendam à questão clínica. Nesse caso, a estratégia corresponde ao que é denominado de busca sensível, sendo mais utilizada para pesquisas e para elaboração de revisões sistemáticas.
Entretanto, se o objetivo for obter número menor de referências, mas de maior relevância, deve ser realizada uma estratégia de busca mais específica, com a utilização dos limitadores apropriados. Nesse caso, o tempo, em relação à amplitude, será privilegiado, podendo gerar a possibilidade de perder artigos relevantes.

A metodologia da MBE propõe critérios de classificação para as pesquisas científicas, de acordo com as evidências encontradas nos estudos. Os diferentes tipos de pesquisa são representados na pirâmide da evidência (figura 2).

Os trabalhos devem obedecer à ordem decrescente de importância, ou seja, um trabalho que se encontra no nível de evidência I terá maior valor científico do que um que se encontra no nível V. Nessa perspectiva, na seleção da informação deve ser considerado o nível de evidência em que ela se encontra.

Na pirâmide a ordem de relevância dos desenhos de pesquisa em relação à MBE é ascendente, enquanto a quantidade de literatura disponível é descendente. Assim, temos que, à medida que vai diminuindo a quantidade de informação disponível, vai aumentando a relevância dessas informações para a prática médica.

\section{FIGURA 2}

\section{Pirâmide da evidência}

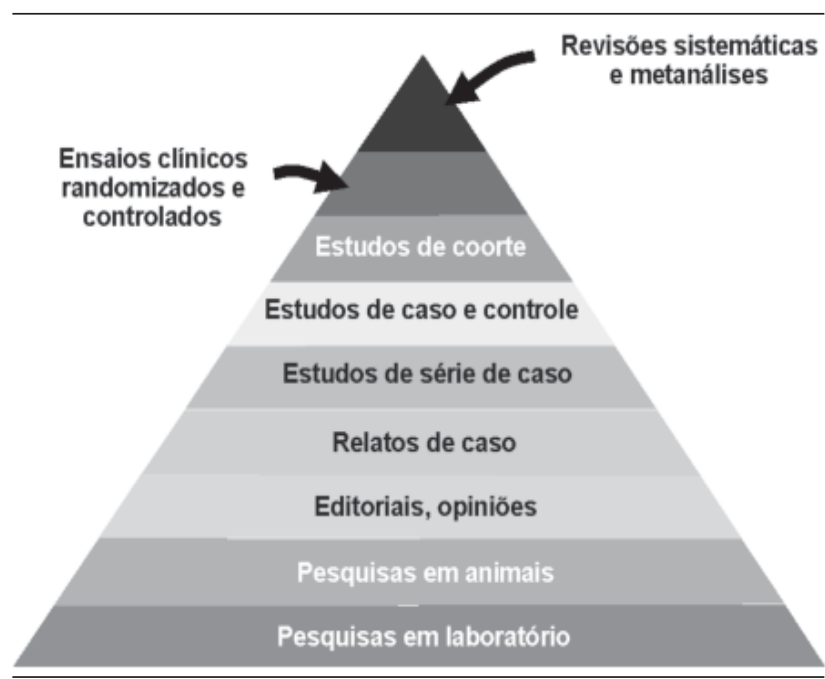

Fonte: Adaptada de SUNY (2001, tradução nossa). 
Para Rodrigues (2000), os ensaios clínicos randomizados e as revisões sistemáticas são os que provêem os médicos clínicos com informação mais coerente e com maior evidência para a intervenção clínica.

Um ensaio é dito randomizado e controlado quando os pacientes são distribuídos de forma aleatória nos grupos de intervenção ou experimental (uso de agente causal) e nos grupos de controle (uso de placebo ou outro agente) (FLETCHER; FLETCHER, 1996; SUNY, 2001; MARTINEZSILVEIRA, 2003; SILVA, 2002; DRUMMOND, 2004a; 2004b).

A revisão sistemática caracteriza-se como um trabalho científico que utiliza uma metodologia rigorosa de análise, classificação e categorização dos estudos sobre o tema, com o objetivo de evitar vieses. As revisões sistemáticas podem ou não utilizar métodos estatísticos - metanálises (ATALLAH; CASTRO, 1998).

Dentre as publicações utilizadas na área médica que revisam e analisam publicações, destacam-se os textbooks baseados em evidências e os guidelines ou diretrizes da prática clínica. Os textbooks baseados em evidências revisam as melhores evidências da literatura e geralmente estão relacionados à terapêutica e à prevenção. Os guidelines ou diretrizes de prática clínica, baseados em revisões sistemáticas ou metanálises e isentos de vieses e interesses corporativistas ou comerciais, constituem valiosa fonte de informação para a decisão clínica.

\section{PROCEDIMENTOS METODOLÓGICOS}

A pesquisa desenvolvida caracterizou-se como exploratória e descritiva, do ponto de vista de seus objetivos, e quanti-qualitativa com relação à abordagem do problema.

Segundo Tobar e Romano Yalour (2001), a pesquisa exploratória é aquela realizada em áreas e sobre problemas dos quais há pouco ou nenhum conhecimento acumulado e sistematizado, exigindo do investigador familiarização com o assunto.
Já a pesquisa descritiva expõe características de determinada população ou fenômeno.

Para Minayo et al. (2005, p. 71), "o método quantitativo visa a obter evidências de associações entre variáveis independentes (intervenção, exposição) e dependentes (resposta ou de desfecho)". O método qualitativo, mesmo que apresente diferentes estratégias metodológicas, tem como objetivo "compreender as relações, as visões e o julgamento dos diferentes atores sobre a intervenção da qual participam, entendendo que suas vivências e reações fazem parte da construção da intervenção e de seus resultados" (MINAYO et al., 2005, p. 82).

Do ponto de vista dos procedimentos técnicos, esta pesquisa se apresenta como levantamento (survey). Esse tipo de pesquisa caracteriza-se pela interrogação realizada diretamente com o grupo cujo comportamento se deseja conhecer (GIL, 1997).

O universo da pesquisa foi constituído por 41 médicos residentes matriculados no Programa de Residência Médica (RM) do Hospital Universitário (HU) Professor Polydoro Ernani de São Thiago da UFSC, que atuam na prática clínica ambulatorial.

A escolha pelos médicos residentes como grupo de estudo se deu, principalmente, pelo reduzido número de pesquisas brasileiras sobre o tema e pelo fato de que, no período de residência, o profissional tem oportunidade de colocar em prática o aprendizado do curso de graduação, o que permite extrair forte indicador do grau de conhecimentos adquiridos durante a graduação; e está receptivo para absorver novos aprendizados, mostrando grande interesse na resolução de questões clínicas, seja para incorporar novos conhecimentos ou para sua afirmação profissional.

Para o processo de coleta de dados, foram utilizados dois instrumentos: o questionário e a entrevista semiestruturada. Na entrevista foi utilizada a técnica do incidente crítico, que compreende a identificação de situações particularmente relevantes, observadas ou relatadas por um indivíduo. Segundo Flanagan 
(1973), a técnica do incidente crítico permite obter fatos importantes relacionados ao comportamento do indivíduo.

Para analisar os incidentes críticos se definiram quatro grandes categorias:

1) fontes de informação consultadas;

2) critérios utilizados para seleção das fontes de informação;

3) recursos utilizados para acesso às fontes de informação;

4) contribuição da informação encontrada para a decisão clínica ou para mudança de decisão anterior.

\section{O FLUXO DA INFORMAÇÃO NA PRÁTICA CLÍNICA DOS MÉDICOS RESIDENTES DO HU/UFSC E OS PRECEITOS DA MBE}

A partir da análise dos dados, elaborou-se o fluxo da informação na prática clínica dos médicos residentes do HU da UFSC, no atendimento ambulatorial (figura 3). Considerando as variáveis de maior incidência apontadas nesta pesquisa e as linhas metodológicas referendadas pela MBE, foram indicadas até três variáveis (mais representativas) para cada item analisado.

Para mapear e contextualizar a etapa 2, "Acesso à Informação", foram indicadas todas as etapas recomendadas pela $\mathrm{MBE}$, com análise dos itens pertinentes à pesquisa. Portanto, alguns itens das etapas 1, 3 e 4, quando relacionados direta ou indiretamente com o acesso à informação, foram mencionados. Na etapa $1 \mathrm{fez}$-se menção ao enfoque da questão clínica, na etapa 3 aos desenhos de pesquisa mais utilizados, e na etapa 4 à aplicabilidade da resolução da questão clínica. A etapa 5, referente à autoavaliação, não foi mencionada pelos médicos residentes como etapa integrante do fluxo informacional.

Pelo esboço do fluxo verifica-se que, na formulação da questão clínica, os enfoques estão relacionados com aspectos clínicos em nível de foreground: tratamento, diagnóstico e prevenção, em detrimento de aspectos genéricos das patologias. Essa análise, embora não pertencendo diretamente à fase de acesso à informação, é imprescindível para nortear

FIGURA 3

Fluxo da informação na prática clínica ambulatorial dos médicos residentes do HU da UFSC

Paciente/

Caso clinico
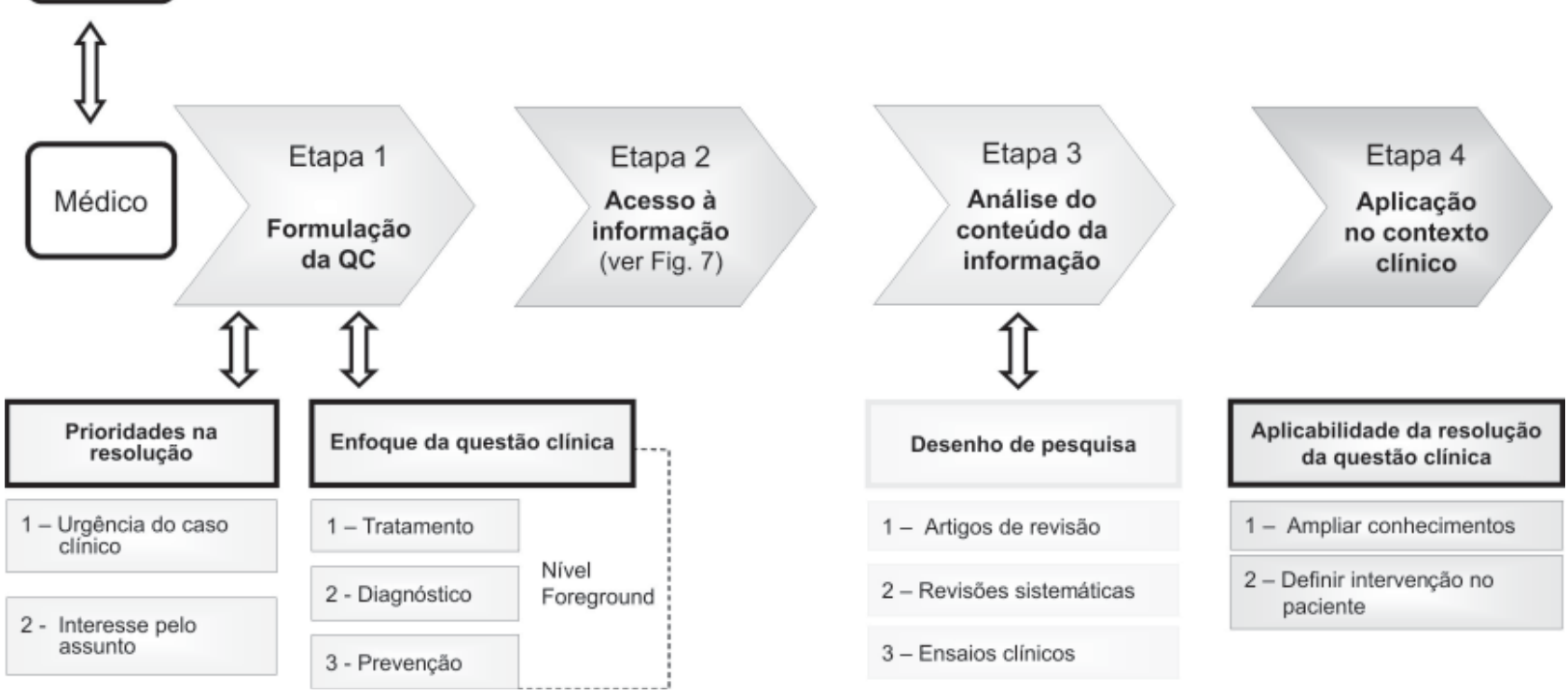

Aplicabilidade da resolução da questão clínica

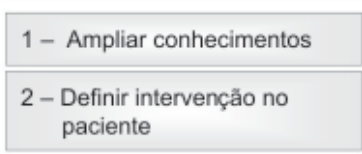

Fonte: Elaboração das autoras. 
a continuidade do processo, haja vista que cada um desses enfoques (diagnóstico, tratamento, prognóstico e prevenção) requer diferentes abordagens na seleção das informações relevantes.

O fluxo definido reflete os resultados da pesquisa realizada indicando que:

- a prioridade das questões clínicas está relacionada à urgência do caso clínico e ao interesse do profissional pelo caso clínico;

- os desenhos de pesquisa mais utilizados são as revisões narrativas, as revisões sistemáticas e os ensaios clínicos. As revisões narrativas, devido às suas características, necessitam de mais cuidado na seleção de seu conteúdo;

- a aplicação da resolução da questão clínica no contexto ocorre com a ampliação dos conhecimentos do médico residente e na definição de intervenção no paciente.
Para melhor identificar a etapa 2, Acesso à Informação, ponto focal de análise, foi elaborado um fluxo específico, identificado na figura 4.

Para iniciar o processo de resolução da questão clínica, os médicos residentes do HU da UFSC se deparavam com problemas estruturais e conjunturais que interferiam, particularmente, no acesso à informação: a falta de computadores nos ambulatórios e a sobrecarga de trabalho.

A seleção das fontes de informação tinha por base aspectos relacionados com a atualidade da informação, a confiabilidade dos autores (autores de renome científico) e a acessibilidade (facilidade de acesso) à fonte de informação.

Na seleção das fontes de informação, eles utilizavam inicialmente os periódicos, textbooks/handbooks, guidelines, preceptores e pares. Porém, quando se defrontavam com dificuldades para selecionar ou recuperar as fontes de informação que atendessem sua questão clínica (resultado negativo), buscavam

FIGURA 4

Fluxo da informação na prática clínica ambulatorial dos médicos residentes do HU da UFSC na etapa 2 da MBE: acesso à informação

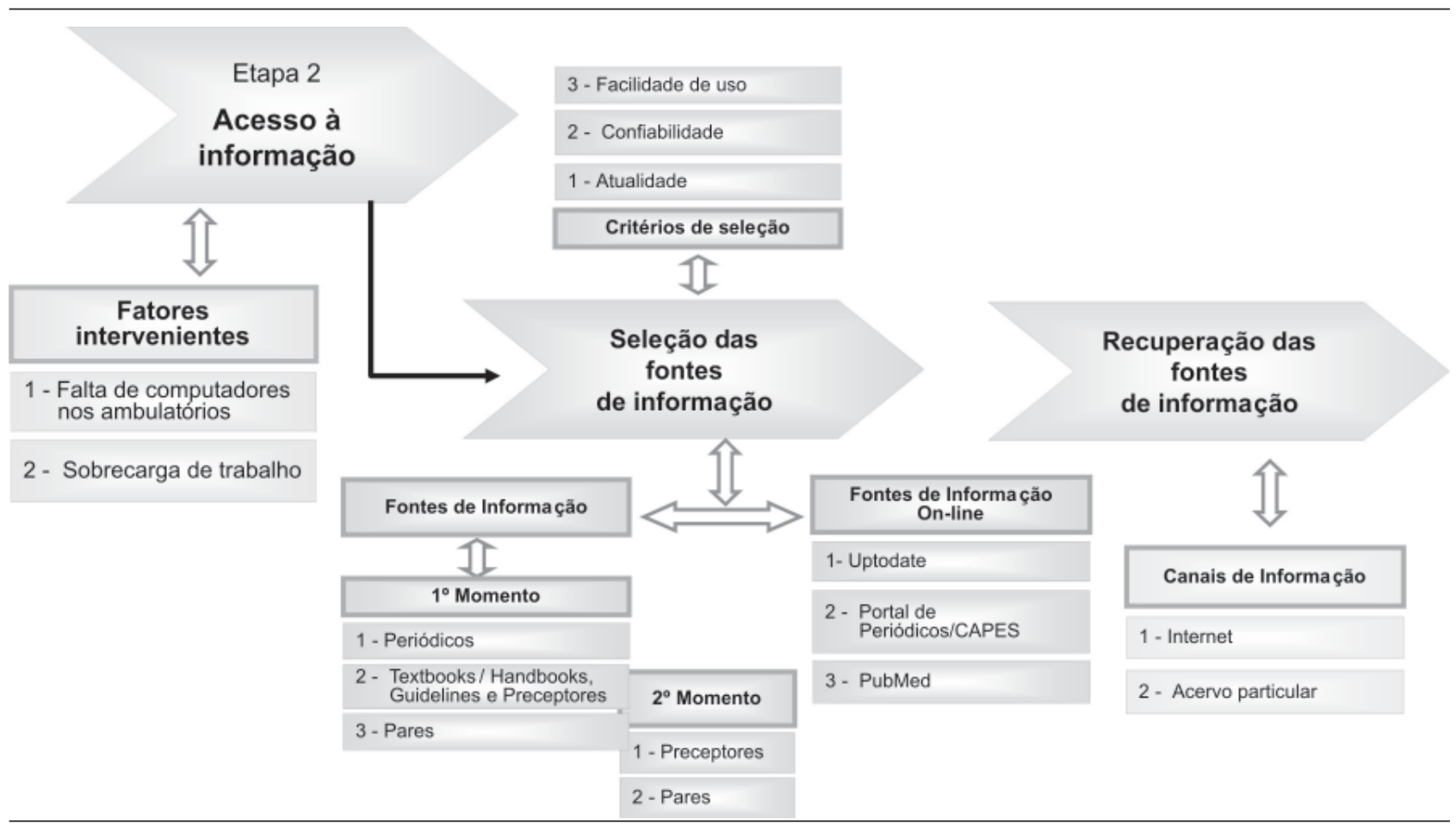

Fonte: Elaboração das autoras. 
ajuda nos preceptores e nos pares. Dentre essas fontes de informação, os periódicos, os guidelines e os textbooks (se forem os baseados em evidência) podem ser considerados potenciais fontes de informação de evidências científicas.

Dentre os sistemas informatizados, os médicos do HU da UFSC indicaram, por maior incidência de uso, a base de dados Uptodate, portanto uma fonte de informação terciária, conforme a classificação da Bireme utilizada nesta pesquisa. No uso do Portal de Periódicos da Capes, pode-se inferir que estavam utilizando as fontes primárias do Portal, mediante sua coleção de periódicos, haja vista que foi o tipo de fonte de informação mais indicada nesta pesquisa. A representatividade das fontes secundárias ocorreu com o uso do PubMed.

Para acessar e recuperar as fontes de informação, os médicos residentes se valiam de canais formais e informais de informação por meio da Internet, e dos canais formais através dos pares e acervo particular. Sobre o uso das potencialidades das bases de dados, faziam uso parcial das ferramentas disponíveis.

O fluxo da informação dos médicos residentes do HU da UFSC (figuras 3 e 4) indica que estavam sendo utilizados alguns preceitos da MBE, mesmo que de forma pouco sistematizada. De maneira geral, pode-se afirmar que os médicos residentes estavam procurando introduzir parte dos processos da MBE, particularmente com relação à etapa 2 , em sua prática clínica ambulatorial, muitas vezes de maneira implícita e não consciente da prática.

Analisando o fluxo de informação da prática clínica ambulatorial do médico residente do HU da UFSC e os preceitos da MBE, percebe-se que algumas ações necessitam ser implementadas ou aperfeiçoadas a fim de que o processo seja mais eficiente:

- melhorias na infraestrutura dos ambulatórios, especialmente na disponibilização de computadores conectados à Internet, permitindo ao médico que tenha acesso à informação on-line durante o atendimento ao paciente, quando assim se fizer necessário;

Ci. Inf., Brasília, DF, v. 38, n. 3, p.177-191, set./dez., 2009
- maior diversidade no uso de outras fontes de informação disponíveis e relevantes em evidência científica, especialmente as on-line e fontes terciárias, já que, atualmente, a concentração de uso ocorre somente em três bases de dados/portais: Uptodate, Portal de Periódicos da Capes e PubMed;

- maior conhecimento do escopo das fontes de informação disponíveis, a fim de subsidiar a seleção $\mathrm{da}(\mathrm{s})$ fonte(s) mais indicada(s) para responder à questão clínica;

- desenvolvimento e/ou aperfeiçoamento de habilidades e de conhecimentos específicos das ferramentas das fontes de informação para busca e recuperação da informação nos sistemas informatizados, potencializando o resultado da pesquisa com o uso de estratégias mais elaboradas e direcionadas;

- maior integração da biblioteca como agente envolvido em todo o processo.

Com base em tais considerações, projeta-se um modelo considerado ideal de fluxo otimizado da informação na prática clínica ambulatorial dos médicos residentes do HU da UFSC, de acordo com os preceitos da MBE, abordando a etapa 2, "Acesso à Informação" (figura 5).

Nessa projeção foi considerada uma situação ideal no que se refere à infraestrutura dos ambulatórios, à disponibilidade de fontes de informação e de serviços de biblioteca adequados.

A metodologia da MBE na prática clínica tem início na relação médico/paciente. A informação causal e informal do paciente passa pelo médico que, aliando sua experiência clínica individual, a transforma numa questão clínica e vai em busca de outra informação, a informação científica, a fim de subsidiar sua decisão clínica.

A questão clínica deverá ser formulada considerando itens que compõem o PICO, já que cada elemento é fundamental para compor a decisão clínica, seja ela relacionada com diagnóstico, terapêutica, prognóstico ou prevenção. 
FIGURA 5

Proposta ideal de fluxo informação na prática clínica ambulatorial dos médicos residentes do HU da UFSC na etapa 2 da MBE: acesso à informação

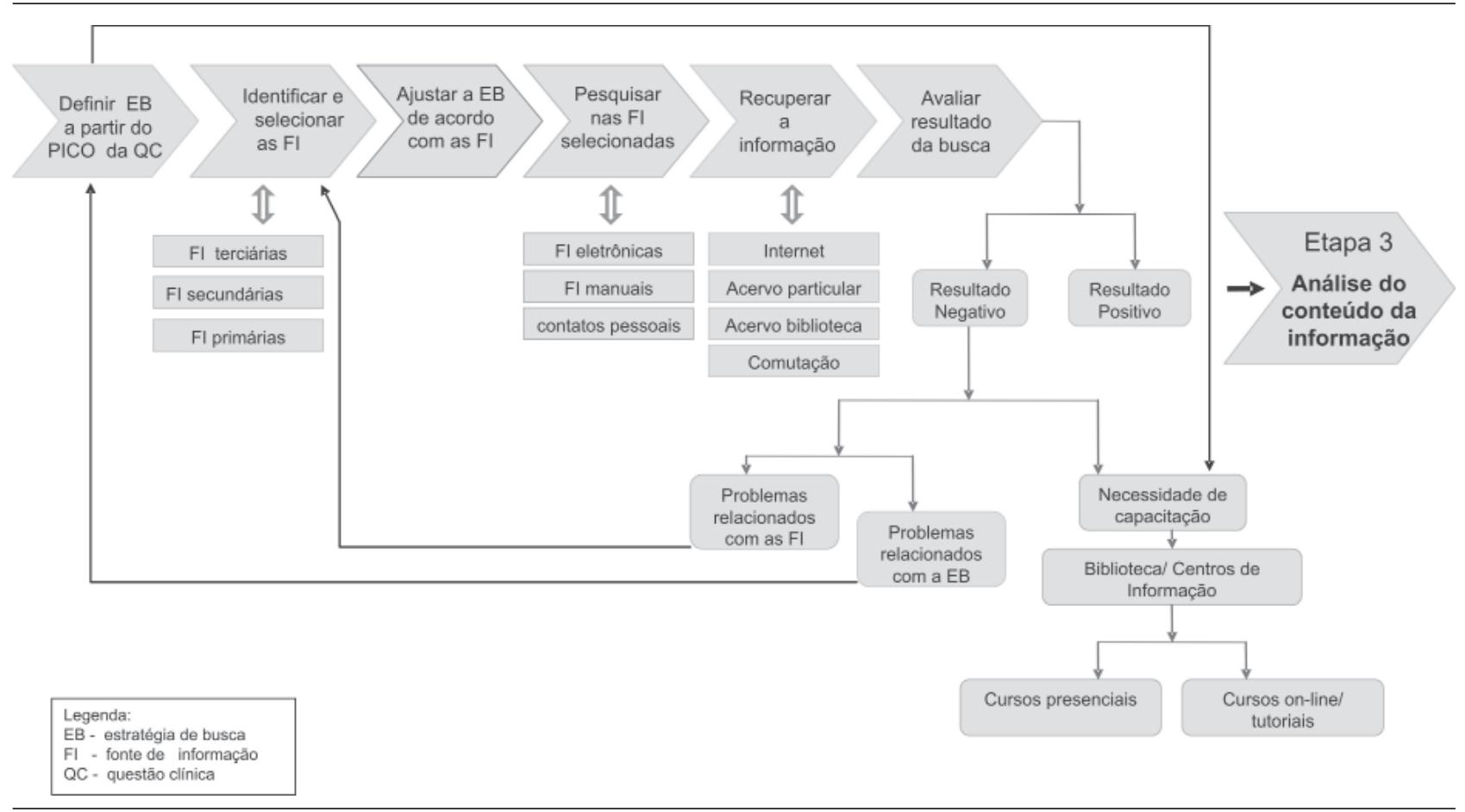

Fonte: Elaboração das autoras.

Os desenhos de pesquisas, mesmo estando diretamente relacionados à etapa de análise de conteúdo, estão indiretamente relacionados com o enfoque da questão clínica e com a seleção da fonte de informação apropriada para aquele enfoque.

Na etapa de "Acesso à Informação" foram estabelecidas as seguintes ações:

- definir a estratégia de busca a partir da questão clínica;

- identificar e selecionar as fontes de informação pertinentes;

- ajustar a estratégia de busca de acordo com as fontes de informação selecionadas; realizar a pesquisa nas fontes de informação selecionadas;

- recuperar as informações;

- avaliar o resultado da busca informacional.

Para iniciar a etapa de acesso à informação, é fundamental que o médico residente tenha conhecimentos e habilidades para uso das fontes de informação, especificamente para definição da estratégia de busca e seleção das fontes de informação pertinentes, a fim de potencializar o resultado da busca.

Caso não disponha desses conhecimentos e habilidades, recomenda-se que o médico residente busque capacitação, escolhendo para isso cursos presenciais e/ou cursos on-line, normalmente oferecidos por bibliotecas/centros de informação. Se já estiver habilitado, deverá definir a(s) estratégia(s) de busca a partir do PICO identificado na elaboração da questão clínica. Deverão ser levantadas as possíveis palavraschave apropriadas para recuperação da informação do tema escolhido e definido o uso de operadores booleanos para possibilitar as combinações lógicas pertinentes. Outros itens, como limitadores referentes à faixa etária, ao sexo, aos idiomas, por exemplo, também poderão ser utilizados.

De posse dos dados da estratégia de busca e visando ao objetivo da questão clínica, o médico residente 
deverá identificar e selecionar as mais pertinentes e disponíveis fontes de informação. $\mathrm{O}$ acesso às fontes de informação terciárias deve ser priorizado, por diminuir o tempo de busca, permitir acesso à informação que já passou por avaliação crítica de conteúdo e por já estar sintetizada. As fontes de informação secundárias também têm seu papel de destaque, porém o médico residente deverá dispor de mais tempo para analisar e sintetizar a informação. Algumas fontes secundárias de informação já dispõem de filtros direcionados para questões clínicas. As fontes de informação primária são mais indicadas para questões clínicas de caráter genérico.

Após selecionar as fontes de informação a serem utilizadas, o médico residente deverá ajustar a(s) estratégia(s) de busca para cada fonte de informação selecionada, haja vista que podem apresentar recursos diferentes. Nessa ação, é fundamental a familiaridade com as ferramentas disponíveis, considerando que estratégias de buscas bem elaboradas tendem a maximizar o resultado da busca. Deve estar claro para o médico se a busca pretende ser mais sensível ou mais específica.

Numa situação ideal, o uso de fontes e/ou sistemas de informação on-line deve ser priorizado, e os médicos residentes devem ter habilidade para dominar todos ou grande parte dos recursos disponíveis nos sistemas informatizados, especialmente para resolver as questões mais complexas. Dependendo da abrangência da questão clínica, uma pesquisa em uma fonte de informação manual ou o contato pessoal com pares, preceptores e outros profissionais poderá ser a solução.

Ações para recuperar as informações que foram consideradas relevantes, especialmente em bases de dados bibliográficas que não dispõem de texto completo, incluem as opções de recuperar na Internet, no acervo particular, no acervo da biblioteca ou solicitar através de algum serviço de comutação bibliográfica.

Ao avaliar o resultado da busca, o médico residente estará diante de duas situações: o resultado foi positivo, atingindo os objetivos e recuperando documentos pertinentes ao tema; ou o resultado foi negativo, não atingindo os objetivos e não recuperando documentos pertinentes ou em número insuficiente. No resultado negativo, se o problema estiver relacionado às fontes de informação, ou seja, as fontes selecionadas não atenderam a contento, ele deve retornar para a ação "selecionar as fontes de informação"; se for detectado que o problema está relacionado à estratégia de busca, deve retornar para a ação "definir estratégia de busca". Porém, se o médico residente considerar que seus conhecimentos e habilidades não foram suficientes para ter um bom resultado de busca, deve procurar a biblioteca/centro de informação para treinamento através de cursos presenciais ou on-line, conforme for mais conveniente.

\section{CONSIDERAÇÕES FINAIS}

Esta pesquisa não teve como intenção levantar críticas ou fazer defesa da MBE. Apenas reconhece a aproximação existente entre uma das fases desse modelo de prática clínica com os serviços prestados e/ou viabilizados pelas unidades de informação especializadas em saúde. Dessa forma, cabe lembrar que o foco das lentes de observação e de análise da pesquisa esteve ajustado para detectar os processos dessa fase específica, ou seja, da fase de acesso à informação.

O fluxo informacional observado na prática clínica ambulatorial dos médicos residentes do HU da UFSC converge com o que Barreto (2002) denomina fluxos extremos da informação, pois notadamente a informação utilizada pelo médico residente provoca uma mudança de status na situação anterior. Essa mudança está relacionada diretamente com a aquisição de novos conhecimentos pelo médico, mais em nível de foreground, e com a aplicabilidade desses conhecimentos nas intervenções do paciente.

O fluxo informacional na prática clínica dos médicos residentes apresenta uma estrutura que se reporta a alguns preceitos recomendados pela MBE, particularmente a etapa referente ao uso das fontes 
de informação, porém de forma muito incipiente e pouco sistematizada. A falta de conhecimentos mais específicos sobre as potencialidades de uso das fontes de informação e do aproveitamento mais intenso de fontes de informação em evidência são pontos que poderiam estar mais integrados à prática clínica, a fim de ampliar o espectro de informações que possam levar à melhor conduta a ser aplicada.

Os cursos de graduação e os programas de residência médica devem estar atentos para tais dificuldades e proporcionar o desenvolvimento de competências, para que os médicos estejam preparados para avaliação e uso da literatura médica, e de todos os recursos informacionais acessíveis.

Na prática clínica, pelo fluxo traçado, a ausência da indicação da biblioteca, como um dos agentes envolvidos no processo de busca de informação para responder a uma questão clínica, demonstra a necessidade de sua integração ativa nesse processo como agente importante nessa cadeia informacional.

A operacionalização de uma proposta de fluxo informacional ideal irá requer que sejam revistas políticas institucionais de modo que estas priorizem o acesso à informação como uma importante estratégia para oferecer serviços de saúde mais eficientes e proporcionar benefícios aos pacientes.

Artigo submetido em 01/06/2009 e aceito em 23/03/2010.

\section{REFERÊNCIAS}

ATALLAH, Álvaro Nagib; CASTRO, Aldemar Araújo. Evidências para melhores decisões clínicas. São Paulo: Lemos, 1998.

BARRETO, Aldo de Albuquerque. Mudança estrutural no fluxo do conhecimento: a comunicação eletrônica. Ciência da Informação, Brasília, v. 27, n. 2 , p.122-127, 1998.

Os destinos da Ciência da Informação: entre o cristal e a chama. Informação \& Sociedade: Estudos. João Pessoa, v. 9, n. 2, p. 371-382, jul./dez. 1999.

O tempo e o espaço da ciência da informação. Transinformação, Campinas. v. 14, n. 1, p. 17-24, jun., 2002

BAUMAN, Zygmunt. Modernidade líquida. Rio de Janeiro: Jorge Zahar, 2001.
BERTO, Rosa Maria Villares de Souza. Novas práticas de comunicação e produção de publicações científicas. In: CONGRESSO BRASILEIRO DE CIÊNCIAS DA COMUNICAÇÃO, 26., 2003, Belo Horizonte. Anais... Belo Horizonte: INTERCOM, 2003. p 1-18.

BIREME. Guia 2001 de desenvolvimento da Biblioteca Virtual em Saúde. São Paulo, 2001. Disponível em: <http://www3.bireme.br/bvs/reuniao/ doc/guiabvs2001.doc >. Acesso em: 7 jun. 2007.

CASTELLS, Manuel. A sociedade em rede. 6. ed. São Paulo: Paz e Terra, 2002. v.1.

CASTRO, Aldemar Araújo; CLARCK, Otávio Augusto Câmara. Localizando informações para a prática clínica. In: __ Fiat lux. Maceió: UNCISAL, 2006. Cap. 9. Disponível em: < http:/ / www. metodologia.org/livro/>. Acesso em: 13 dez. 2007.

DRUMMOND, José Paulo. O que é medicina baseada em evidências? In:___ SILVA, Eliézer; COUTINHO, Mário. Medicina baseada em evidências: novo paradigma assistencial e pedagógico. 2. ed. São Paulo: Atheneu, 2004a. Cap. 1.

Ensaio clínico: estrutura, funcionamento e análise. In:__. Medicina baseada em evidências: novo paradigma assistencial e pedagógico. 2. ed. São Paulo: Atheneu, 2004b. Cap. 7.

DUNCAN, Bruce B.; SCHMIDT, Maria Inês. Medicina baseada em evidências. In: __ et al. Medicina ambulatorial: condutas clínicas em atenção primária baseadas em evidências. 3. ed. Porto Alegre: ArtMed, 2004. Cap. 1.

EVIDENCE-BASED MEDICINE WORKING GROUP. Evidence-based medicine: a new approach to teaching the practice of medicine. Journal of the American Medical Association, Chicago, v. 268, n. 17, p. 2420-2425, Nov. 1992.

FLANAGAN, John C. A técnica do incidente crítico. Arquivos brasileiros de psicologia aplicada, Rio de Janeiro, v. 21, n. 2, p. 99-141, 1973.

FLETCHER, Robert H.; FLETCHER, Suzanne W.; WAGNER, Edward H. Epidemiologia clínica: elementos essenciais. 3. ed. Porto Alegre: Artes Médicas, 1996.

GARVEY, William D. Communication: the essence of science. Oxford: Pergamon, 1979.

GIL, Antonio Carlos. Métodos e técnicas de pesquisa social. 3. ed. São Paulo: Atlas, 1997.

LOPES, Ilza Leite. Estratégia de busca na recuperação da informação: revisão da literatura. Ciência da Informação, Brasília, v. 31, n. 2, p. 60-71, maio/ago. 2002.

MARASCIULO, Antonio Carlos Estima; NASSAR, Sílvia Modesto. Conceitos básicos em bioestatística e em epidemiologia clínica. In: DRUMMOND, José Paulo; SILVA, Eliézer; COUTINHO, Mário. Medicina baseada em evidências: novo paradigma assistencial e pedagógico. 2. ed. São Paulo: Atheneu, 2004. Cap. 5. 
MARQUES, Roni. Os riscos da medicina sem a ciência médica. Bioética, Brasília, v. 11, n. 2, 2003.

MARTINEZ-SILVEIRA, Martha Silvia. O bibliotecário e a medicina baseada em evidências. In: ENCONTRO NACIONAL DE CIÊNCIA DA INFORMAÇÃO. 4., 2003, Salvador. Anais... Salvador: UFBA, 2003.

McKIBBON, Ann. Evidence-based practice. Bulletin of Medical Library Association, Chicago, v. 86, n. 3, p. 396-401, July 1998. Disponível em: $<$ http://www.pubmed central.nih.gov/picrender.fcgi?artid=226388 \&blobtype $=$ pdf $>$. Acesso em: 27 mar. 2007.

MINAYO, Maria Cecília de Souza et al. Métodos, técnicas e relações em triangulação. In: ; ASSIS, Simone Gonçalves de; SOUZA, Edinilsa Ramos de. Avaliação por triangulação de métodos: abordagens de programas sociais. Rio de Janeiro: Fiocruz, 2005. p. 71-103.

MUELLER, Suzana Pinheiro Machado. A ciência, o sistema de comunicação científica e a literatura científica. In: CAMPELLO, B. S.; CÉNDON, B. V.; KREMER, J. M. Fontes de Informação para pesquisadores e profissionais. Belo Horizonte: UFMG, 2000. p. 21-34.

NOBRE, Moacyr Roberto; BERNARDO, Wanderley Marques; JATENE, Fábio Biscegli. A prática clínica baseada em evidências: parte 1: questões clínicas bem construídas. Revista da Associação Médica Brasileira, São Paulo, v. 49, n. 4, p. 445-449, 2003.

RODRIGUES, Roberto J. Information systems: the key to evidencebased health practice. Bulletin of the World Health Organization, Geneve, v. 78 , n. 11, p. 1344-1351, 2000.
SACKETT, David L. et al. Evidence-based medicine: how to practice and teach EBM. Edinburgh: Churchill Livingstone, 1998.

Medicina baseada em evidências: prática e ensino. 2. ed. Porto Alegre: Artmed, 2003.

SANTOS, Boaventura de Sousa. Os processos da globalização. In: (Org.). A globalização e as Ciências Sociais. 2. ed. São Paulo: Cortez, 2002. p. 25-102.

SILVA, Edna Lúcia da; MENEZES, Estera Muszkat. Metodologia da pesquisa e elaboração de dissertação. 4. ed. rev. atual. Florianópolis: UFSC, 2005.

Eliézer. Como avaliar e interpretar a literatura médica. In: DRUMMOND, José Paulo; SILVA, Eliézer; COUTINHO, Mário. Medicina baseada em evidências: novo paradigma a SUNY Downstate Medical Center. Evidence Based Medicine Course ssistencial e pedagógico. 2. ed. São Paulo: Atheneu, 2002. Cap. 3.

SUNY DOWNSTATE MEDICAL CENTER. Evidence Based Medicine Course Evidence pyramid. 2001. Disponível em: < http://library. downstate.edu/EBM2/2100 .htm>. Acesso em: 26 mar. 2007.

TARGINO, Maria das Graças. Comunicação científica: uma revisão de seus elementos básicos. Informação e Sociedade: Estudos, João Pessoa, v. 10, n. 2 , p. $67-85,2000$.

TOBAR, Federico; ROMANO YALOUR, Margot. Como fazer teses em saúde pública. Rio de Janeiro: Fiocruz, 2001. 